\title{
Article \\ Mediators of Racial Differences in COVID-19 Vaccine Acceptance and Uptake: A Cohort Study in Detroit, MI
}

\author{
Abram L. Wagner ${ }^{1}{ }^{*} \mathbb{D}$, Lydia Wileden ${ }^{2} \mathbb{D}$, Trina R. Shanks ${ }^{3} \mathbb{D}$, Susan Door Goold ${ }^{4}$, Jeffrey D. Morenoff ${ }^{2}$ \\ and Sherri N. Sheinfeld Gorin ${ }^{5}$
}

check for updates

Citation: Wagner, A.L.; Wileden, L.; Shanks, T.R.; Goold, S.D.; Morenoff, J.D.; Gorin, S.N.S. Mediators of Racial Differences in COVID-19 Vaccine Acceptance and Uptake: A Cohort Study in Detroit, MI. Vaccines 2022, 10, 36. https://doi.org/10.3390/ vaccines 10010036

Academic Editors: Ger Rijkers and Jean-Luc Murk

Received: 23 November 2021 Accepted: 22 December 2021 Published: 28 December 2021

Publisher's Note: MDPI stays neutral with regard to jurisdictional claims in published maps and institutional affiliations.

Copyright: (C) 2021 by the authors. Licensee MDPI, Basel, Switzerland. This article is an open access article distributed under the terms and conditions of the Creative Commons Attribution (CC BY) license (https:// creativecommons.org/licenses/by/ $4.0 /)$.
1 Department of Epidemiology, School of Public Health, University of Michigan, 1415 Washington Heights, Ann Arbor, MI 48109, USA

2 Department of Sociology, Gerald R. Ford School of Public Policy, Institute for Social Research, University of Michigan, Ann Arbor, MI 48109, USA; lwileden@umich.edu (L.W.); morenoff@umich.edu (J.D.M.)

3 School of Social Work, University of Michigan, Ann Arbor, MI 48109, USA; trwilli@umich.edu

4 Department of Internal Medicine, Michigan Medicine, Ann Arbor, MI 48109, USA; sgoold@umich.edu

5 Department of Family Medicine, Michigan Medicine, Ann Arbor, MI 48109, USA; ssgorin@med.umich.edu

* Correspondence: awag@umich.edu

\begin{abstract}
Despite their disparate rates of infection and mortality, many communities of color report high levels of vaccine hesitancy. This paper describes racial differences in COVID-19 vaccine uptake in Detroit, and assesses, using a mediation model, how individuals' personal experiences with COVID-19 and trust in authorities mediate racial disparities in vaccination acceptance. The Detroit Metro Area Communities Study (DMACS) is a panel survey of a representative sample of Detroit residents. There were 1012 respondents in the October 2020 wave, of which 856 (83\%) were followed up in June 2021. We model the impact of race and ethnicity on vaccination uptake using multivariable logistic regression, and report mediation through direct experiences with COVID as well as trust in government and in healthcare providers. Within Detroit, only $58 \%$ of Non-Hispanic (NH) Black residents were vaccinated, compared to $82 \%$ of Non-Hispanic white Detroiters, $50 \%$ of Hispanic Detroiters, and $52 \%$ of other racial/ethnic groups. Trust in healthcare providers and experiences with friends and family dying from COVID-19 varied significantly by race/ethnicity. The mediation analysis reveals that $23 \%$ of the differences in vaccine uptake by race could be eliminated if $\mathrm{NH}$ Black Detroiters were to have levels of trust in healthcare providers similar to those among NH white Detroiters. Our analyses suggest that efforts to improve relationships among healthcare providers and NH Black communities in Detroit are critical to overcoming local COVID-19 vaccine hesitancy. Increased study of and intervention in these communities is critical to building trust and managing widespread health crises.
\end{abstract}

Keywords: African Americans; vaccination coverage; minority groups; mediation analysis

\section{Introduction}

More than 18 months after the first case of the coronavirus disease 2019 (COVID-19) was identified in the U.S., COVID-19 and its variants continue to spike cases and mortality rates across the country and around the globe. Research has shown that COVID-19 has disproportionately affected racial and ethnic minority groups [1]. Despite their disparate rates of infection and mortality, many communities of color report high levels of vaccine hesitancy.

Within the US, Wayne county, Michigan-home to Detroit-ranks 22nd in the number of confirmed COVID-19 cases and 8th in deaths, with a case to fatality ratio of $2.40 \%$ [2]. In Detroit, where more than $78 \%$ of the population is non-Hispanic (NH) Black and more than one third (36\%) living in poverty [3], there have been nearly 52,000 confirmed COVID-19 cases and 2312 deaths. Detroit remains a COVID-19 case and mortality "hot spot", yet vaccine uptake remains low. As of 28 July 2021, vaccination coverage within Detroit is $33 \%$, compared to $54 \%$ for the state as a whole [4]. 
Low COVID vaccine uptake is not unique to Detroit. A number of international and national surveys have reported population-wide findings on the intention to take COVID-19 vaccines, which is a strong predictor of vaccination behavior [5]. A U.S. survey from March 2021 by Kaiser found that $62 \%$ of Americans have been vaccinated or intend to be, including $55 \%$ of non-Hispanic Black adults, $61 \%$ of Hispanic adults, and $64 \%$ of NH white adults [6].

Vaccine hesitancy is also not unique to COVID-19. The seasonal flu vaccine is the closest analogue to what an optional COVID-19 vaccine program could look like. The average adult uptake of the seasonal flu vaccine throughout the U.S., and within Michigan, during 2019-2020 was approximately $48 \%$ [7]. Coverage is about 8-9\% lower in the $\mathrm{NH}$ Black population than NH whites [8]. Although past research has identified that disparities in vaccination behaviors and vaccine hesitancy exist by race and ethnicity [9], to our knowledge, few have rigorously studied the causal mechanisms behind vaccine hesitancy among those most affected-urban NH Black and Hispanic populations [10]. Moreover, the current COVID-19 pandemic offers a unique perspective on disparities faced within certain populations as a result of the scale and reach of this public health crisis.

To study minority communities' receipt of a COVID-19 vaccine, we draw on a unique resource: a robust survey of Detroit fielded throughout the COVID-19 pandemic, including prior to the wide-scale implementation of vaccination programs. We describe racial/ethnic disparities in COVID-19 vaccine uptake in Detroit. We systematically assess, using a mediation model, if individuals' personal experiences with COVID-19 and trust in health authorities prior to vaccine roll-out mediate racial and ethnic disparities in vaccination uptake. We hypothesize that experience with COVID-19 and trust in healthcare providers and/or government health officials are important mediators of racial and ethnic differences in vaccine uptake. Given continued sub-optimal uptake of the COVID19 vaccine, these findings can continue to inform current efforts to reduce COVID-19 vaccine hesitancy.

\section{Materials and Methods}

\subsection{Data}

The Detroit Metro Area Communities Study (DMACS) is a panel survey of a representative sample of Detroit residents launched in 2016. The original panel of respondents was drawn from an address-based probability sample of all occupied Detroit households. DMACS was designed to descriptively estimate a number of different indicators in a precise fashion; the margin of sampling error for any indicator would be $+/-2.9$ percentage points at the $95 \%$ confidence level, though this would vary by indicator due to the complex sample design. In subsequent years, the panel has been refreshed through additional address-based sampling. Starting in March 2020, less than 3 weeks after the CDC declared the COVID19 pandemic a national emergency and with Detroit emerging as a "hot spot", DMACS launched a series of rapid response surveys to understand Detroiters' experiences with COVID-19. Due to restrictions on face-to-face interactions during the pandemic, outreach was limited to a subset of DMACS panelists who had previously provided email addresses and/or phone numbers as contact information. This paper focuses on data collected in the fifth rapid response COVID-19 survey, when a total of 1641 DMACS panelists were invited to participate. Eligible participants were adult residents of Detroit; 1012 surveys were completed, for a response rate of $62 \%$ (using AAPOR Response Rate 1). Surveys were self-administered online and interviewer-administered by telephone between 14 October and 28 October 2020. Between 2 June and 9 July 2021, individuals were followed up ( $\mathrm{N}=856,83 \%$ of October wave) and asked about actual vaccination uptake. Data have been weighted to reflect the population of the city of Detroit. The questionnaires are available at: https: / / detroitsurvey.umich.edu/findings / (accessed on 15 September 2021). 


\subsection{Vaccine Uptake as the Outcome Measure}

Our main outcome is COVID-19 vaccine uptake, which we measured as initiation of at least one dose of any vaccine by the June 2021 wave. We also measured vaccine intent in October 2020 with the question "How likely are you to get a government-approved COVID19 vaccine when it becomes available?" Responses were captured using a 4-point Likert scale that ranged from "very unlikely" to "very likely". Following related, international studies of COVID-19 [11], we dichotomize this variable to capture if a respondent says they intend to vaccinate or not. Those who stated that they were somewhat or very likely to get vaccinated were categorized as intending to be vaccinated, while those who said somewhat or very unlikely were categorized as unlikely to be vaccinated.

\subsection{Race/Ethnicity}

Our primary independent variable of interest in this paper is respondents' selfidentified race/ethnicity, which we separated into Non-Hispanic Black, NH white, Hispanic, and $\mathrm{NH}$ other, in which we included all other categories, including Asian American, Pacific Islander, or Native American.

\subsection{Mediators}

We considered mediation in terms of six different measures of the participant's personal experience with COVID-19, including two of trust: perceived severity of the COVID19 pandemic, if the respondent had friends or family who had become ill with or who died from COVID-19, if the respondent had been diagnosed with COVID-19, the degree of the respondent's trust in healthcare providers, and the degree of the respondent's trust in government health officials.

\subsection{Covariates}

Other covariates in this model were selected based on their relevance to previous literature [11-13] and the Health Belief Model [14]. The Health Belief Model has posited that individuals will engage in a health behavior, for example, vaccination, if they receive cues to action. These cues may include a recommendation to vaccinate from a healthcare provider.

\section{Statistical Analysis}

Our analysis proceeds in four steps. First, we summarize the sociodemographic characteristics, COVID-19 experiences, trust in authorities, and vaccination intent, stratified across four racial/ethnicity groups.

We model the association between race and ethnicity on vaccination uptake using multivariable logistic regression. Coefficients are captured as odds ratios (ORs) and 95\% confidence intervals (CI). To examine how vaccine intent by race/ethnicity varies with other sociodemographic characteristics, we include interactions between race/ethnicity and gender, race/ethnicity and education, and race/ethnicity and income.

To examine the relative importance of experiences with COVID-19 and trust in healthcare providers and officials on an individual's intention to get vaccinated, we use Rao-Scott Chi-Square tests to test for significant differences across race/ethnicity.

Finally, using mediation models, we assess the influence of our independent variables on COVID-19 vaccine uptake in a series of multivariable logistic regression models. These models are limited to NH Black and NH white Detroiters in order to more precisely deconstruct mediating pathways. Each model separately examined the effect of our six measures of personal experience with COVID-19 and trust in healthcare providers and health authorities, adjusting for gender, age, income, and education. We did not put multiple measures of experiences and trust into the same model, as our a priori consideration was that there would be complex causal processes linking these together, and we wanted to estimate the total effect for each measure. For each of these models, we introduced an interaction term between race/ethnicity and every independent variable or covariate in order to examine 
differences in the association between independent variables and vaccine uptake by race. We present the results stratified by race/ethnicity.

Subsequently, we tested if differences in intent to vaccinate by race/ethnicity were mediated by experiences during COVID-19 or by trust in healthcare providers and health authorities, using the CAUSALMED procedure in SAS [15]. We report the proportion of the race/ethnicity-vaccination uptake relationship mediated and proportion eliminated by these mediating variables. Briefly, the proportion mediated comes from the natural pathway between the exposure (race/ethnicity) and the outcome, and represents what would happen to the strength of association between the exposure and outcome if we could disable the pathway through the mediator. The proportion eliminated is a policy-relevant measure, which represents what would happen to the strength of association between the exposure and outcome if we shifted everyone to counterfactually having the same value for the mediator [16]. All analyses were conducted in SAS version 9.4 (SAS Institute, Cary, NC, USA), with listwise deletion of missing data, and with an alpha level of 0.05 . Our reporting of the study's findings follows the STROBE guidelines for cross-sectional studies (see Supplementary Table S1).

\section{Ethical Review}

The protocol was approved by the University of Michigan Institutional Review Board (\#HUM00112364). Participants read over an informed consent form and agreed to it electronically prior to any data collection.

\section{Results}

Of the 1012 respondents in the October 2020 wave, the majority, $77 \%(N=714)$, identified as NH Black, and the rest identified as $\mathrm{NH}$ white (10\%), Hispanic (8\%), or other (5\%) (Table 1). Within Detroit, 39\% said they intended to get vaccinated once the vaccine became available. NH Black Detroiters expressed the lowest intention to be vaccinated: only $32 \%$ of NH Black residents reported being willing to vaccinate in October 2020, compared to $69 \%$ of NH white Detroiters, $51 \%$ of Hispanic Detroiters, and $45 \%$ of other racial/ethnic groups. A total of $856(83 \%)$ were able to be followed up in the June 2021, with no significant difference in loss-to-follow-up by race/ethnicity. As of June 2021, 58\% had received at least one dose of a COVID-19 vaccine, with uptake highest in $\mathrm{NH}$ white Detroiters (82\%).

Table 1. Demographic characteristics, COVID-19 experiences, trust in healthcare providers and authorities, and vaccination intent, stratified by race/ethnicity, Detroit Metro Area Community Study, October 2020 and June 2021.

\begin{tabular}{|c|c|c|c|c|c|c|c|}
\hline & & Overall & $\begin{array}{c}\text { In NH Black } \\
\text { Detroiters }\end{array}$ & $\begin{array}{l}\text { In NH White } \\
\text { Detroiters }\end{array}$ & $\begin{array}{l}\text { In Hispanic } \\
\text { Detroiters }\end{array}$ & $\begin{array}{l}\text { In Other } \\
\text { Detroiters }\end{array}$ & $p$-Value \\
\hline Overall (row \%) & & & $714(77 \%)$ & $129(10 \%)$ & $57(8 \%)$ & $112(5 \%)$ & \\
\hline \multirow{2}{*}{ Gender } & Male & $287(47 \%)$ & $167(43 \%)$ & $55(71 \%)$ & $12(46 \%)$ & $53(61 \%)$ & \multirow{2}{*}{$<0.0001$} \\
\hline & Female & $723(53 \%)$ & $547(57 \%)$ & $74(29 \%)$ & $45(54 \%)$ & $57(39 \%)$ & \\
\hline \multirow{6}{*}{ Age } & $18-24$ & $61(11 \%)$ & $31(9 \%)$ & $5(5 \%)$ & $14(38 \%)$ & $11(17 \%)$ & \multirow{6}{*}{$<0.0001$} \\
\hline & $25-34$ & $178(23 \%)$ & $100(19 \%)$ & $38(43 \%)$ & $18(35 \%)$ & $22(19 \%)$ & \\
\hline & $35-44$ & $183(17 \%)$ & $114(16 \%)$ & $34(24 \%)$ & $13(16 \%)$ & $22(18 \%)$ & \\
\hline & $45-54$ & $189(14 \%)$ & $154(16 \%)$ & $7(5 \%)$ & $8(8 \%)$ & $20(14 \%)$ & \\
\hline & $55-64$ & $223(15 \%)$ & $178(17 \%)$ & $22(11 \%)$ & $4(4 \%)$ & $19(15 \%)$ & \\
\hline & $\geq 65$ & $168(19 \%)$ & $130(23 \%)$ & $23(12 \%)$ & $0(0 \%)$ & $15(16 \%)$ & \\
\hline \multirow{2}{*}{ Yearly income } & $<$ USD 50,000 & $655(69 \%)$ & $482(75 \%)$ & $62(36 \%)$ & $38(61 \%)$ & $73(74 \%)$ & \multirow{2}{*}{$<0.0001$} \\
\hline & $\geq$ USD 50,000 & $276(31 \%)$ & $178(25 \%)$ & $59(64 \%)$ & $17(39 \%)$ & $22(26 \%)$ & \\
\hline
\end{tabular}


Table 1. Cont.

\begin{tabular}{|c|c|c|c|c|c|c|c|}
\hline & & Overall & $\begin{array}{c}\text { In NH Black } \\
\text { Detroiters }\end{array}$ & $\begin{array}{l}\text { In NH White } \\
\text { Detroiters }\end{array}$ & $\begin{array}{l}\text { In Hispanic } \\
\text { Detroiters }\end{array}$ & $\begin{array}{c}\text { In Other } \\
\text { Detroiters }\end{array}$ & $p$-Value \\
\hline \multirow[b]{2}{*}{ Education } & <Bachelor's degree & $702(83 \%)$ & $522(88 \%)$ & $52(45 \%)$ & $50(89 \%)$ & $78(81 \%)$ & \multirow{2}{*}{$<0.0001$} \\
\hline & $\geq$ Bachelor's degree & $306(17 \%)$ & $192(12 \%)$ & $76(55 \%)$ & $7(11 \%)$ & $31(19 \%)$ & \\
\hline \multirow{5}{*}{$\begin{array}{l}\text { Perceived severity } \\
\text { of COVID-19 }\end{array}$} & Very serious & $695(69 \%)$ & $537(75 \%)$ & $58(39 \%)$ & $36(56 \%)$ & $64(62 \%)$ & \multirow{5}{*}{$<0.0001$} \\
\hline & Somewhat serious & $235(21 \%)$ & $139(19 \%)$ & $51(36 \%)$ & $12(24 \%)$ & $33(22 \%)$ & \\
\hline & Not too serious & $61(7 \%)$ & $23(3 \%)$ & $18(22 \%)$ & $7(18 \%)$ & $13(15 \%)$ & \\
\hline & Not at all serious & $13(2 \%)$ & $9(2 \%)$ & $1(2 \%)$ & $2(2 \%)$ & $1(1 \%)$ & \\
\hline & Don't know & $4(1 \%)$ & $3(1 \%)$ & $1(0 \%)$ & $0(0 \%)$ & $0(0 \%)$ & \\
\hline \multirow{2}{*}{$\begin{array}{l}\text { Friends / family } \\
\text { ever ill from } \\
\text { COVID-19 }\end{array}$} & No & $457(47 \%)$ & $317(47 \%)$ & $63(57 \%)$ & $22(37 \%)$ & $55(45 \%)$ & \multirow[b]{2}{*}{0.2464} \\
\hline & Yes & $555(53 \%)$ & $397(53 \%)$ & $66(43 \%)$ & $35(63 \%)$ & $57(55 \%)$ & \\
\hline \multirow{2}{*}{$\begin{array}{c}\text { Friends / family } \\
\text { died from } \\
\text { COVID-19 }\end{array}$} & No & $626(64 \%)$ & $399(59 \%)$ & $114(93 \%)$ & $38(72 \%)$ & $75(66 \%)$ & \multirow{2}{*}{$<0.0001$} \\
\hline & Yes & $386(36 \%)$ & $315(41 \%)$ & $15(7 \%)$ & $19(28 \%)$ & $37(34 \%)$ & \\
\hline \multirow{2}{*}{$\begin{array}{l}\text { Ever diagnosed } \\
\text { with COVID-19 }\end{array}$} & No & $971(96 \%)$ & $680(96 \%)$ & $126(98 \%)$ & $55(94 \%)$ & $110(99 \%)$ & \multirow{2}{*}{0.4125} \\
\hline & Yes & $41(4 \%)$ & $34(4 \%)$ & $3(2 \%)$ & $2(6 \%)$ & $2(1 \%)$ & \\
\hline \multirow{3}{*}{$\begin{array}{l}\text { Trust healthcare } \\
\text { provider about } \\
\text { COVID-19 }\end{array}$} & Not at all & $62(7 \%)$ & $46(7 \%)$ & $1(0 \%)$ & $6(11 \%)$ & $9(6 \%)$ & \multirow{3}{*}{0.0013} \\
\hline & A little & $355(36 \%)$ & $250(39 \%)$ & $37(27 \%)$ & $18(28 \%)$ & $50(48 \%)$ & \\
\hline & A great deal & $581(56 \%)$ & $407(54 \%)$ & $90(73 \%)$ & $33(61 \%)$ & $51(46 \%)$ & \\
\hline \multirow{3}{*}{$\begin{array}{l}\text { Trust government } \\
\text { about COVID-19 }\end{array}$} & Not at all & $158(18 \%)$ & $118(19 \%)$ & $17(15 \%)$ & $6(13 \%)$ & $17(12 \%)$ & \multirow{3}{*}{0.4161} \\
\hline & A little & $420(40 \%)$ & $279(38 \%)$ & $50(44 \%)$ & $27(48 \%)$ & $64(58 \%)$ & \\
\hline & A great deal & $423(41 \%)$ & $308(42 \%)$ & $62(41 \%)$ & $24(39 \%)$ & $29(31 \%)$ & \\
\hline \multirow{4}{*}{$\begin{array}{c}\text { Intent to be } \\
\text { vaccinated } \\
\text { (October 2020) }\end{array}$} & Very unlikely & $416(38 \%)$ & $343(44 \%)$ & $15(11 \%)$ & $19(25 \%)$ & $39(41 \%)$ & \multirow{4}{*}{$<0.0001$} \\
\hline & Somewhat unlikely & $218(23 \%)$ & $159(25 \%)$ & $25(20 \%)$ & $12(23 \%)$ & $22(14 \%)$ & \\
\hline & Somewhat likely & $231(24 \%)$ & $144(23 \%)$ & $34(22 \%)$ & $22(43 \%)$ & $31(28 \%)$ & \\
\hline & Very likely & $139(14 \%)$ & $61(9 \%)$ & $55(47 \%)$ & $4(8 \%)$ & $19(17 \%)$ & \\
\hline \multirow{2}{*}{$\begin{array}{l}\text { Included in June } \\
2021 \text { wave }\end{array}$} & Included & $856(83 \%)$ & $611(83 \%)$ & $104(81 \%)$ & $51(88 \%)$ & $90(81 \%)$ & \multirow[b]{2}{*}{0.7222} \\
\hline & Lost to follow up & $156(17 \%)$ & $103(17 \%)$ & $25(19 \%)$ & $6(12 \%)$ & $22(19 \%)$ & \\
\hline \multirow{2}{*}{$\begin{array}{l}\text { At least one dose } \\
\text { of COVID-19 } \\
\text { vaccine (June 2021) }\end{array}$} & Yes & $522(58 \%)$ & $356(56 \%)$ & $88(82 \%)$ & $27(50 \%)$ & $51(52 \%)$ & \multirow{2}{*}{0.0042} \\
\hline & No & $325(42 \%)$ & $246(44 \%)$ & $16(18 \%)$ & $24(50 \%)$ & $39(48 \%)$ & \\
\hline
\end{tabular}

Note: NH, non-Hispanic. Missing data are not included.

$\mathrm{NH}$ Black individuals perceived greater severity of COVID-19 than other subgroups, although Hispanics reported more friends and family having become ill from COVID-19 than other groups. Across the racial/ethnic subgroups, few had been diagnosed with COVID-19. NH Black Detroiters reported the largest number of deaths from COVID-19 among family and friends ( $41 \%$ reported this experience, vs. $7 \%$ of $\mathrm{NH}$ white Detroiters, $p<0.0001)$. Trust in healthcare providers significantly differed across racial/ethnic groups $(p=0.0013)$ and was greatest among $\mathrm{NH}$ whites; trust in government was similar across the racial/ethnic groups included in this study $(p=0.4161)$.

Table 2 examines the relationship between race and vaccination uptake, and the interaction between race and other sociodemographic variables on vaccination. Vaccination was relatively low in the $\mathrm{NH}$ Black population, and higher in other race/ethnic groups (e.g., in $\mathrm{NH}$ white vs. $\mathrm{NH}$ Black: $\mathrm{OR}=3.24,95 \% \mathrm{CI}$ : 3.14, 3.33). We also found that vaccine uptake varied significantly by gender, education, and age. 
Table 2. Interactions between race/ethnicity and other sociodemographic variables in vaccine uptake among 784 Detroiters, June 2021.

\begin{tabular}{|c|c|c|c|c|}
\hline Category & OR $(95 \% \mathrm{CI})$ & $p$-Value & OR $(95 \% \mathrm{CI})$ & $p$-Value \\
\hline Race/ethnicity & & $<0.0001$ & & $<0.0001$ \\
\hline NH Black & ref. & & ref. & \\
\hline NH white & $3.24(3.14,3.33)$ & & $5.55(5.26,5.87)$ & \\
\hline Hispanic & $1.54(1.50,1.58)$ & & $2.74(2.62,2.86)$ & \\
\hline Other & $0.71(0.69,0.74)$ & & $0.70(0.66,0.74)$ & \\
\hline Female vs. male & $0.90(0.89,0.92)$ & $<0.0001$ & $1.03(1.01,1.04)$ & 0.0011 \\
\hline Race $\times$ Gender Interaction & & & & $<0.0001$ \\
\hline NH white $\times$ Female & & & $0.32(0.30,0.34)$ & \\
\hline Hispanic $\times$ Female & & & $0.47(0.45,0.49)$ & \\
\hline Other $\times$ Female & & & $1.00(0.93,1.08)$ & \\
\hline College vs. less education & $2.61(2.55,2.67)$ & $<0.0001$ & $2.00(1.94,2.06)$ & $<0.0001$ \\
\hline Race $\times$ Education Interaction & & & & $<0.0001$ \\
\hline NH white $\times$ College & & & $3.80(3.53,4.09)$ & \\
\hline Hispanic $\times$ College & & & $1.23(1.14,1.34)$ & \\
\hline Other $\times$ College & & & $3.84(3.44,4.29)$ & \\
\hline Income $\geq$ USD 50,000 vs. less & $1.74(1.71,1.77)$ & $<0.0001$ & $1.98(1.94,2.02)$ & $<0.0001$ \\
\hline Race $\times$ Income Interaction & & & & $<0.0001$ \\
\hline NH white $\times \geq$ USD 50,000 & & & $0.30(0.28,0.32)$ & \\
\hline Hispanic $\times \geq$ USD 50,000 & & & $0.62(0.59,0.65)$ & \\
\hline Other $\times \geq$ USD 50,000 & & & $0.56(0.52,0.62)$ & \\
\hline Age & & $<0.0001$ & & $<0.0001$ \\
\hline 18-39 years & $0.33(0.33,0.34)$ & & $0.32(0.31,0.32)$ & \\
\hline 40-64 years & ref. & & ref. & \\
\hline$\geq 65$ years & $2.66(2.60,2.71)$ & & $2.61(2.56,2.67)$ & \\
\hline
\end{tabular}

Note: $\mathrm{NH}$, non-Hispanic.

Among NH Black Detroiters, the odds of vaccination were higher in females than males (OR: $1.03,95 \%$ CI: 1.01, 1.04), in those with a college education compared to less schooling (OR: 2.00, 95\% CI: 1.94, 2.06), and in those with an income $\geq$ USD 50,000 vs. less (OR: 1.98, 95\% CI: 1.94, 2.02). The interactions between race and gender, education, or income were all statistically significant. In the aggregate, findings from this interaction analysis point to young, male, NH Black Detroiters with lower education levels and lower income as being less likely to obtain a vaccine, whereas other racial/ethnic groups had different patterns.

Table 3 explores differences in the major predictors of vaccination intention by subgroups of residents. The only factor that produced a statistically significant difference in vaccine intent across racial groups was a recommendation from a healthcare provider $(p<0.0056)$. Most $(90 \%) \mathrm{NH}$ white Detroiters were influenced in their intention to vaccinate by their healthcare providers, compared to $74 \%$ of Hispanic Detroiters, $77 \%$ of others, and $67 \%$ of NH Black Detroiters. Differences in personal experience with COVID-19 did not produce significant differences in the likelihood of vaccinating. 
Table 3. Importance of additional factors in an individual's intention to become vaccinated, stratified by race/ethnicity, and by gender among Black Detroiters, October 2021.

\begin{tabular}{|c|c|c|c|c|c|}
\hline & \multicolumn{5}{|c|}{ Among All Detroiters } \\
\hline & NH Black (\%) & NH White (\%) & Hispanic (\%) & Other (\%) & $p^{\mathrm{a}}$ \\
\hline & 714 & 159 & 57 & 112 & \\
\hline Country where vaccine produced & $437(61 \%)$ & $76(62 \%)$ & $40(74 \%)$ & $68(57 \%)$ & 1 \\
\hline Recommendation from healthcare provider & $473(67 \%)$ & $111(90 \%)$ & $40(74 \%)$ & $77(69 \%)$ & 0.0056 \\
\hline Recommendation from government health officials & $371(56 \%)$ & $90(68 \%)$ & $38(69 \%)$ & $51(50 \%)$ & 0.7960 \\
\hline Vaccine used for long time with no serious side effects & $568(81 \%)$ & $111(82 \%)$ & $47(86 \%)$ & $87(83 \%)$ & 1 \\
\hline COVID-19 risk of infection when vaccine is available & $531(75 \%)$ & $93(72 \%)$ & $41(70 \%)$ & $78(70 \%)$ & 1 \\
\hline Time and place of vaccination & $444(66 \%)$ & $70(56 \%)$ & $39(67 \%)$ & $65(60 \%)$ & 1 \\
\hline Vaccine is free & $415(62 \%)$ & $67(45 \%)$ & $41(65 \%)$ & $67(56 \%)$ & 0.6376 \\
\hline Know other people getting vaccinated & $351(51 \%)$ & $50(39 \%)$ & $34(62 \%)$ & $55(53 \%)$ & 1 \\
\hline
\end{tabular}

Notes: NH, non-Hispanic. ${ }^{a} p$-value from Rao-Scott Chi-Square Test, controlled for multiple testing through a Bonferroni correction factor of 8 .

In six multivariable regression models with the six measures of COVID-19 personal experiences and perceived trust in healthcare providers and health authorities (Table 4), we found that, overall, most of these measures were significantly related to vaccine uptake, but the strength of association differed between NH Black and NH white Detroiters. For example, in white Detroiters, perceived severity of COVID-19 was significantly associated with vaccine uptake (OR: $2.30,95 \%$ CI: 2.21, 2.39), but this association was null for Black Detroiters (OR: 0.98, 95\% CI: 0.94, 1.01). Similarly, having friends and family who had died from COVID-19 was a pre-disposing factor for NH white Detroiters but the opposite was so for NH Black Detroiters. For trust in healthcare providers and trust in government health officials, there were stronger, positive associations for Black Detroiters than among other racial/ethnic subgroups.

Table 4. Odds of vaccine uptake by COVID-19 experiences and trust in healthcare providers and authorities, in NH Black and NH white Detroiters in the Detroit Metro Area Community Study, October 2020 and June 2021.

\begin{tabular}{ccccccc}
\hline & & \multicolumn{2}{c}{ Odds Ratio of COVID-19 Vaccine Uptake } & & $\begin{array}{c}\text { Mediation of Race-Vaccination } \\
\text { Uptake Relationship }\end{array}$ \\
\hline & N & $\begin{array}{c}\text { In NH Black } \\
\text { Detroiters }\end{array}$ & $\begin{array}{c}\text { In NH white } \\
\text { Detroiters }\end{array}$ & $p$-Value a & \% Mediated & $\%$ Eliminated \\
\hline Perceived COVID-19 severe vs. not & 654 & $0.98(0.94,1.01)$ & $2.30(2.21,2.39)$ & $<0.0001$ & $-1 \%$ & $54 \%$ \\
\hline Friends/family ever ill from COVID-19 vs. not & 656 & $1.45(1.43,1.48)$ & $1.23(1.19,1.27)$ & $<0.0001$ & $0 \%$ & $13 \%$ \\
\hline Friends/family died from COVID-19 vs. not & 656 & $0.76(0.75,0.77)$ & $1.42(1.36,1.47)$ & $<0.0001$ & $2 \%$ & $-2 \%$ \\
\hline Ever diagnosed with COVID-19 vs. not & 656 & $1.03(0.99,1.07)$ & $0.04(0.04,0.05)$ & $<0.0001$ & $0 \%$ & $0 \%$ \\
\hline Trust healthcare provider a great deal vs. not & 649 & $2.65(2.61,2.70)$ & $1.45(1.40,1.49)$ & $<0.0001$ & $6 \%$ & \\
\hline Trust government health officials a great deal vs. not & 650 & $2.84(2.79,2.89)$ & $0.74(0.72,0.77)$ & $<0.0001$ & $3 \%$ & $23 \%$ \\
\hline
\end{tabular}

Notes: Each row represents a separate model; each model controlled for gender, age, income, and education as covariates. Mediators assessed in October 2020, outcome in June 2021. ' for interaction of race and main effect, i.e., difference in strength of association between Black and white Detroiters. NH, non-Hispanic.

Trust in healthcare providers explained $6 \%$ of the differences in vaccine uptake between NH Black and NH white Detroiters. The mediation analysis revealed that $23 \%$ of the differences in vaccine uptake by race could be eliminated if NH Black Detroiters were to have levels in trust in healthcare providers similar to those among white NH Detroiters. Trust in government health officials showed a similar pattern: there was a minimal (3\%) 
amount of mediation. Importantly, increasing the levels of trust in NH Black Detroiters to those observed in white Detroiters could eliminate $18 \%$ of the difference in vaccine uptake.

\section{Discussion}

Using a robust, probability-based sample from Detroit, we evaluated the mediators of COVID-19 vaccine to better understand the causes of vaccine hesitancy in a multiethnic, multi-racial urban sample with high vaccine hesitancy. We are among the first to systematically assess, using causal models, the impact of these mediators, including the personal, lived experience, on separate ethnic and racial subsamples of an urban population. We found less influence of perceived COVID-19 severity on vaccination among NH Black Detroiters by comparison to their NH white counterparts. Trust in a healthcare provider and trust in government health officials were stronger predictors of vaccine uptake among $\mathrm{NH}$ Blacks relative to $\mathrm{NH}$ whites; however, levels of trust in healthcare providers were relatively low among NH Black Detroiters. Through the mediation analysis, we identified a substantial impact of trust on mediating the difference in uptake between $\mathrm{NH}$ Blacks and NH whites. These findings could undergird policy approaches, public health communications, and community- and individual-level intervention approaches that are targeted to specific population subgroups to decrease vaccination hesitancy.

The published literature on COVID-19 vaccine uptake has found that higher hesitancy is associated with younger age $[12,13,17]$. We also found that higher income NH Blacks were more likely to intend to vaccinate relative to NH Blacks with lower income. Greater resources generally confer increased access to healthcare; these advantages do not necessarily accrue equally to Blacks and whites, particularly in communities with a history of structural racial inequities such as Detroit. Our interaction analysis reveals more income-based disparities among NH Black Detroiters than other races or ethnicities. Further, in the early phase of the pandemic, there were inconsistent public health messages about the importance of vaccines, the likelihood of Operation Warp Speed producing enough vaccines, the mechanisms for obtaining a vaccination, and the number and type of vaccination sites, which may have reduced the impact of wealth on COVID-19 vaccination intent among NH Black respondents. Perceptions about vaccine effectiveness are also important for determining willingness to be vaccinated [18]; the speed of vaccine development could influence how effective or safe individuals think these vaccines are.

Trust in healthcare providers and governmental health officials emerged as an important reason behind vaccine acceptance among those groups most adversely affected by COVID-19. Black Detroiters are at increased risk of being infected, as well as suffering from negative direct or indirect consequences of COVID-19 [19,20]. There is an urgent need for policy and community-based approaches that could be measured by the benchmarks we specified in this study, for example, to decrease vaccine hesitancy among NH Black Detroit residents. Additional public health research could explore the determinants of hesitancy over time, using culturally sensitive measures, as there could also be many alternative reasons why $\mathrm{NH}$ Black and $\mathrm{NH}$ white Detroiters may have differences in vaccine uptake, including issues of access. These could include difficulties in transportation, time costs for obtaining a vaccine, and lack of insurance [21-23]. Addressing these inequities will require investments in areas such as increasing vaccine subsidies and insurance coverage, more local vaccine sites, as well as testing culturally and linguistically sensitive vaccination messages.

We note that reasons for COVID-19 vaccine uptake and hesitancy can vary widely and the results from our study in Detroit do not necessarily translate to other populations. However, research from across the world has found that hesitancy is greater in lower income countries [24] and poorer communities within countries [25]. COVID-19 vaccine acceptance and uptake could also be affected by social media, mistrust of the government in general, and attitudes towards the pharmaceutical industry [26]. Future research could also provide more detail into the reasons why individuals are hesitant, and what reasons are most important. 


\section{Limitations}

A strength of our study was the robust probability-based study that offered us the ability to look at a large population of NH Black Americans and compare their responses to other subgroups who are living in the same urban settings. We also measured our mediating variables prior to the outcome, vaccine uptake. However, we examine a limited set of potential mediators or reasons behind vaccine hesitancy. We also examined the COVID-19 personal experiences and trust as separate mediators, but they could also be examined in future research at the same time in a larger model. Additionally, there could be biases in loss to follow up, which could affect the generalizability of the results. Prior influenza vaccination is a strong predictor of adult COVID-19 vaccination; we did not measure this factor in the survey so cannot assess its influence in this sample. There also could be other unmeasured confounders. We note that our measure of uptake was slightly higher than contemporary measures from the Michigan Department of Health and Human Services, although this could be due to bias from our survey or from the state records [27].

\section{Conclusions}

Given the estimated required population vaccination threshold of $70-80 \%$ for herd immunity, our analyses demonstrated the need for increased study of, and intervention in, the NH Black Detroit community. Our analyses suggest the critical importance of trust-in healthcare providers and government health communications and leaders-for vaccine acceptance among those subgroups most adversely affected by COVID-19. Future research could provide more context into the reasons behind vaccine hesitancy and their relative strength. Yet, findings from this study reveal that improved community relationships between healthcare providers and Black residents could reduce COVID-19 vaccine hesitancy. With the pandemic threat still active, the need is urgent.

Supplementary Materials: The following are available online at https:/ /www.mdpi.com/article/10 .3390 /vaccines10010036/s1, Table S1: STROBE Statement-Checklist of items that should be included in reports of cohort studies.

Author Contributions: Conceptualization, A.L.W., J.D.M.; Methodology, A.L.W., J.D.M.; Software, J.D.M., L.W.; Validation, J.D.M., L.W.; Formal Analysis, A.L.W.; Investigation, A.L.W., J.D.M., L.W., S.N.S.G.; Resources, J.D.M.; Data Curation, A.L.W., J.D.M.; Writing-Original Draft Preparation, S.N.S.G., A.L.W.; Writing-Review and Editing, S.N.S.G., A.L.W., T.R.S., S.D.G., J.D.M., L.W.; Visualization, A.L.W., S.N.S.G.; Supervision, A.L.W., J.D.M., S.N.S.G.; Project Administration, J.D.M., A.L.W., S.N.S.G.; Funding Acquisition, J.D.M., S.N.S.G., A.L.W. All authors have read and agreed to the published version of the manuscript.

Funding: ALW's salary was supported by an award from the National Science Foundation, Division of Social and Economic Sciences (\#2027836). SSG was supported in part by Michigan Institute for Clinical and Health Research grant UL1TR002240. The study sponsors had no role in the design of the study.

Institutional Review Board Statement: The protocol was approved by the Institutional Review Board (\#HUM00112364). Participants read over an informed consent form and agreed to participate in the survey electronically prior to any data collection.

Informed Consent Statement: Written informed consent has been obtained from the patients to publish this paper.

Data Availability Statement: The data are available through: https:/ /doi.org/10.3886/ICPSR37687.v1 (accessed on 15 September 2021).

Acknowledgments: We acknowledge the role of the data collection team in enrolling participants prior to the outbreak of the COVID-19 pandemic.

Conflicts of Interest: The authors declare no competing interest. 


\section{References}

1. Tai, D.B.G.; Shah, A.; Doubeni, C.A.; Sia, I.G.; Wieland, M.L. The Disproportionate Impact of COVID-19 on Racial and Ethnic Minorities in the United States. Clin. Infect. Dis. 2021, 72, 703-706. [CrossRef]

2. Michigan.gov. Coronavirus: Michigan Data. 2020. Available online: https://www.michigan.gov/coronavirus/0,9753,7-406-981 63_98173---,00.html (accessed on 28 October 2020).

3. US Census. QuickFacts Detroit City, Michigan. 2019. Available online: https://www.census.gov/quickfacts/detroitcitymichigan (accessed on 30 October 2020).

4. Michigan Department of Health and Human Services. Coronavirus-COVID-19 Vaccine Dashboard. 2021. Available online: https:/ / www.michigan.gov / coronavirus /0,9753,7-406-98178_103214-547150--,00.html (accessed on 28 July 2021).

5. Liao, Q.; Cowling, B.J.; Lam, W.W.T.; Fielding, R. Factors affecting intention to receive and self-reported receipt of 2009 pandemic (H1N1) vaccine in Hong Kong: A longitudinal study. PLoS ONE 2011, 6, e17713. [CrossRef] [PubMed]

6. Kaiser Health News. Covid Vaccine Hesitancy Drops among All Americans, New Survey Shows. Kaiser Health News. 2021. Available online: https://khn.org/news/article/covid-vaccine-hesitancy-drops-among-americans-new-kff-survey-shows/ (accessed on 28 July 2021).

7. Centers for Disease Control and Prevention (CDC). 2019-2020 Influenza Season Vaccination Coverage Report. 2020. Available online: https:/ / www.cdc.gov/flu/fluvaxview/reportshtml/reporti1920/reporti/index.html (accessed on 10 November 2020).

8. Grohskopf, L.A.; Liburd, L.C.; Redfield, R.R. Addressing Influenza Vaccination Disparities during the COVID-19 Pandemic. JAMA 2020, 324, 1029-1030. [CrossRef] [PubMed]

9. Quinn, S.C.; Jamison, A.M.; An, J.; Hancock, G.R.; Freimuth, V.S. Measuring vaccine hesitancy, confidence, trust and flu vaccine uptake: Results of a national survey of White and African American adults. Vaccine 2019, 37, 1168-1173. [CrossRef] [PubMed]

10. Cameron, K.A.; Rintamaki, L.S.; Kamanda-Kosseh, M.; Noskin, G.A.; Baker, D.W.; Makoul, G. Using theoretical constructs to identify key issues for targeted message design: African American seniors' perceptions about influenza and influenza vaccination. Health Commun. 2009, 24, 316-326. [CrossRef] [PubMed]

11. Stojanovic, J.; Boucher, V.G.; Gagne, M.; Gupta, S.; Joyal-Desmarais, K.; Paduano, S.; Aburub, A.S.; Sheinfeld Gorin, S.N.; Kassianos, A.P.; Ribeiro, P.A.B.; et al. Global Trends and Correlates of COVID-19 Vaccination Hesitancy: Findings from the iCARE Study. Vaccines 2021, 9, 661. [CrossRef] [PubMed]

12. Bish, A.; Yardley, L.; Nicoll, A.; Michie, S. Factors associated with uptake of vaccination against pandemic influenza: A systematic review. Vaccine 2011, 29, 6472-6484. [CrossRef] [PubMed]

13. Sallam, M. COVID-19 Vaccine Hesitancy Worldwide: A Concise Systematic Review of Vaccine Acceptance Rates. Vaccines 2021, 9 , 160. [CrossRef] [PubMed]

14. Janz, N.K.; Becker, M.H. The Health Belief Model: A decade later. Health Educ Q. 1984, 11, 1-47. [CrossRef] [PubMed]

15. SAS Institute Inc. User's Guide The CAUSALMED Procedure. In SAS/STAT ${ }^{\circledR} 14.3$ User's Guide; SAS Institute Inc.: Cary, NC, USA, 2017; Available online: https:/ / support.sas.com/documentation/onlinedoc/stat/143/causalmed.pdf(accessed on 22 December 2020).

16. Vander Weele, T.J. Policy-relevant proportions for direct effects. Epidemiology 2013, 24, 175-176. [CrossRef] [PubMed]

17. Lazarus, J.V.; Ratzan, S.C.; Palayew, A.; Gostin, L.O.; Larson, H.J.; Rabin, K.; Kimball, S.; El-Mohandes, A. A global survey of potential acceptance of a COVID-19 vaccine. Nat. Med. 2021, 27, 225-228. [CrossRef] [PubMed]

18. Wagner, A.L.; Sheinfeld Gorin, S.; Boulton, M.L.; Glover, B.A.; Morenoff, J.D. Effect of vaccine effectiveness and safety on COVID-19 vaccine acceptance in Detroit, Michigan, July 2020. Hum. Vaccines Immunother. 2021, 17, 2940-2945. [CrossRef] [PubMed]

19. Whitehead, M.; Taylor-Robinson, D.; Barr, B. Poverty, health, and COVID-19. BMJ 2021, 372, n376. [CrossRef] [PubMed]

20. Caserotti, M.; Girardi, P.; Rubaltelli, E.; Tasso, A.; Lotto, L.; Gavaruzzi, T. Associations of COVID-19 risk perception with vaccine hesitancy over time for Italian residents. Soc. Sci Med. 2021, 272, 113688. [CrossRef] [PubMed]

21. Abdulai, A.S.; Mukhtar, F.; Ehrlich, M. Decreased racial and ethnic disparities in emergency department wait time in the United States. Med. Care 2022, 60, 13-21. [CrossRef] [PubMed]

22. Sommers, B.D.; Mc Murtry, C.L.; Blendon, R.J.; Benson, J.M.; Sayde, J.M. Beyond health insurance: Remaining disparities in US health care in the post-ACA era. Milbank Q. 2017, 95, 43-69. [CrossRef] [PubMed]

23. Sparling, A.; Walls, M.; Mayfield, C.A.; Priem, J.S.; Durham, J.; Hetherington, T.; Taylor, Y.J. Racial/Ethnic Disparities in Health Care Setting Choice for Adults Seeking Severe Acute Respiratory Syndrome Coronavirus 2 Testing. Med. Care 2022, 60, 3-12. [CrossRef] [PubMed]

24. Riad, A.; Abdulqader, H.; Morgado, M.; Domnori, S.; Koščík, M.; Mendes, J.J.; Klugar, M.; Kateeb, E.; on behalf of IADS-SCORE. Global prevalence and drivers of dental students' COVID-19 vaccine hesitancy. Vaccines 2021, 9, 566. [CrossRef] [PubMed]

25. Kerekes, S.; Ji, M.; Shih, S.-F.; Chang, H.-Y.; Harapan, H.; Rajamoorthy, Y.; Singh, A.; Kanwar, S.; Wagner, A.L. Differential effect of vaccine effectiveness and safety on COVID-19 vaccine acceptance across socioeconomic groups in an international sample. Vaccines 2021, 9, 1010. [CrossRef] [PubMed] 
26. Riad, A.; Pokorná, A.; Antalová, N.; Krobot, M.; Zviadadze, N.; Serdiuk, I.; Koščík, M.; Klugar, M. Prevalence and drivers of COVID-19 vaccine hesitancy among Czech university students: National cross-sectional study. Vaccines 2021, 9, 948. [CrossRef] [PubMed]

27. University of Michigan. COVID-19 Rapid Response Survey: Vaccination and Trust in Information on COVID-19 in Detroit. 2021. Available online: https:/ / detroitsurvey.umich.edu/wp-content/uploads/2021/07/DMACS-Vaccination-and-Trust-Brief-July2021.pdf (accessed on 22 November 2021). 